\title{
Adult polyglucosan body disease associated with an extrapyramidal syndrome
}

\author{
N P Robertson, S Wharton, J Anderson, N J Scolding
}

\begin{abstract}
A 50 year old patient is described who presented with parkinsonism, frontal dementia, peripheral neuropathy, neurogenic bladder, and upper motor neuron signs. No improvement in objective measurements of extrapyramidal dysfunction were seen with an incremental apomorphine test or more prolonged oral dopamine challenge. Neurophysiology disclosed changes compatible with a diffuse axonal neuropathy and pathological examination of a length of sural nerve taken at biopsy showed multiple polyglucosan bodies characteristic of adult polyglucosan body disease (APGBD). This case underlines the diverse clinical presentation of this rare neurological disease and the importance of recognising the unusual association of clinical features in making the diagnosis. APGBD should be included in the differential diagnosis of parkinsonism unresponsive to dopaminergic therapy.

(f Neurol Neurosurg Psychiatry 1998;65:788-790)
\end{abstract}

Keywords: adult polyglucosan body disease, parkinsonism

Reported cases of adult polyglucosan body disease

University of Cambridge Neurology Unit

N P Robertson

N J Scolding

Department of

Neuropathology,

Addenbrooke's

Hospital, Hills Road,

Cambridge, UK

$S$ Wharton

J Anderson

Correspondence to:

Dr N Robertson, University

of Cambridge, Neurology

Unit, Addenbrooke's

Hospital, Hills Road,

Cambridge CB2 2QQ, UK

Telephone 00441223

216751; fax 00441223

336941.

Received 5 February 1998 and in revised form

7 May 1998

Accepted 15 May 1998
Adult polyglucosan body disease (APGBD) was first described in $1980^{1}$ and remains a rare neurological disease with some 25 cases so far reported (table). It derives its name from the accumulation of rounded intra-axonal inclusion bodies in the central and peripheral nervous system. Its most consistent features are onset in the fifth to seventh decades (88\%), peripheral neuropathy $(80 \%)$, dementia $(64 \%)$, neurogenic bladder $(72 \%)$, and upper motor neuron signs $(80 \%),{ }^{2}$ although most patients have one or more of these features missing and some rarer clinical phenomena have been noted. Here we report on a woman with classic features of APGBD and the unusual association of an extrapyramidal syndrome underlining the diverse clinical presentation of this disease.

\section{Case history}

A fifty year old woman who until six months previously had worked as a teacher initially presented with a 2 year history of speech disturbance consisting of slow, low volume speech. One year later she had developed poor balance, frequent falls, tremor predominantly affecting her right hand, urinary urgency, and

\begin{tabular}{|c|c|c|c|c|c|c|c|}
\hline Author & $\begin{array}{l}\text { Age at } \\
\text { onset }\end{array}$ & $\operatorname{Sex}$ & $\begin{array}{l}\text { Upper motor } \\
\text { neuron signs }\end{array}$ & Neuropathy & Dementia & $\begin{array}{l}\text { Urinary } \\
\text { dysfunction }\end{array}$ & Other \\
\hline Suzuki et al ${ }^{18}$ & 59 & $M$ & + & + & + & - & \\
\hline Peres $e t a l^{19}$ & 47 & $M$ & + & + & + & + & \\
\hline \multirow{4}{*}{ Robitaille $e t a l^{1}$} & 43 & M & + & + & + & + & \\
\hline & 47 & $\mathrm{~F}$ & + & + & + & - & \\
\hline & 51 & $\mathrm{~F}$ & + & + & - & + & \\
\hline & 45 & $\mathrm{~F}$ & + & + & - & + & \\
\hline Okamoto et al $l^{0}$ & 64 & $\mathrm{~F}$ & + & + & + & + & \\
\hline Vos et $a l^{9}$ & 46 & $\mathrm{~F}$ & + & + & + & + & \\
\hline \multirow[t]{3}{*}{ Gray et $a l^{10}$} & 68 & M & + & + & - & + & \\
\hline & 63 & M & + & + & + & + & \\
\hline & 74 & $\mathrm{~F}$ & - & + & + & + & \\
\hline \multirow{2}{*}{ Cafferty et $a l^{2}$} & 53 & $\mathrm{~F}$ & + & + & - & + & \\
\hline & 44 & $\mathrm{~F}$ & + & + & - & + & \\
\hline \multirow[t]{2}{*}{ Lossos et $a l^{11}$} & 51 & $M$ & + & + & + & + & Amyotrophy \\
\hline & 55 & $\mathrm{~F}$ & + & + & + & + & \\
\hline \multirow[t]{2}{*}{ Sugiyoma $e t a l^{1}$} & 71 & $\mathrm{~F}$ & + & - & + & - & Optic atrophy \\
\hline & 47 & $\mathrm{~F}$ & - & - & - & - & \\
\hline \multirow[t]{4}{*}{ Bruno et $a l^{17}$} & 38 & $\mathrm{~F}$ & + & + & - & + & Cerebellar atrophy \\
\hline & 50 & $\mathrm{M}$ & - & + & - & - & \\
\hline & 40 & M & + & + & + & + & Cerebellar signs \\
\hline & 84 & M & + & + & + & + & Amyotrophy \\
\hline \multirow{2}{*}{ McDonald et $a l^{13}$} & 50 & $\mathrm{~F}$ & + & - & + & - & Amyotrophy \\
\hline & 66 & $\mathrm{~F}$ & + & + & + & + & Amyotrophy \\
\hline Matsumuro et al ${ }^{2}$ & 70 & $\mathrm{~F}$ & - & + & - & - & \\
\hline \multirow[t]{2}{*}{ Boulan-Predseil et $a l^{16}$} & 65 & $\mathrm{~F}$ & - & - & + & + & \\
\hline & & M:F 1:2.8 & $20 / 25(80 \%)$ & $21 / 25(84 \%)$ & $16 / 25(64 \%)$ & $18 / 25(72 \%)$ & \\
\hline
\end{tabular}



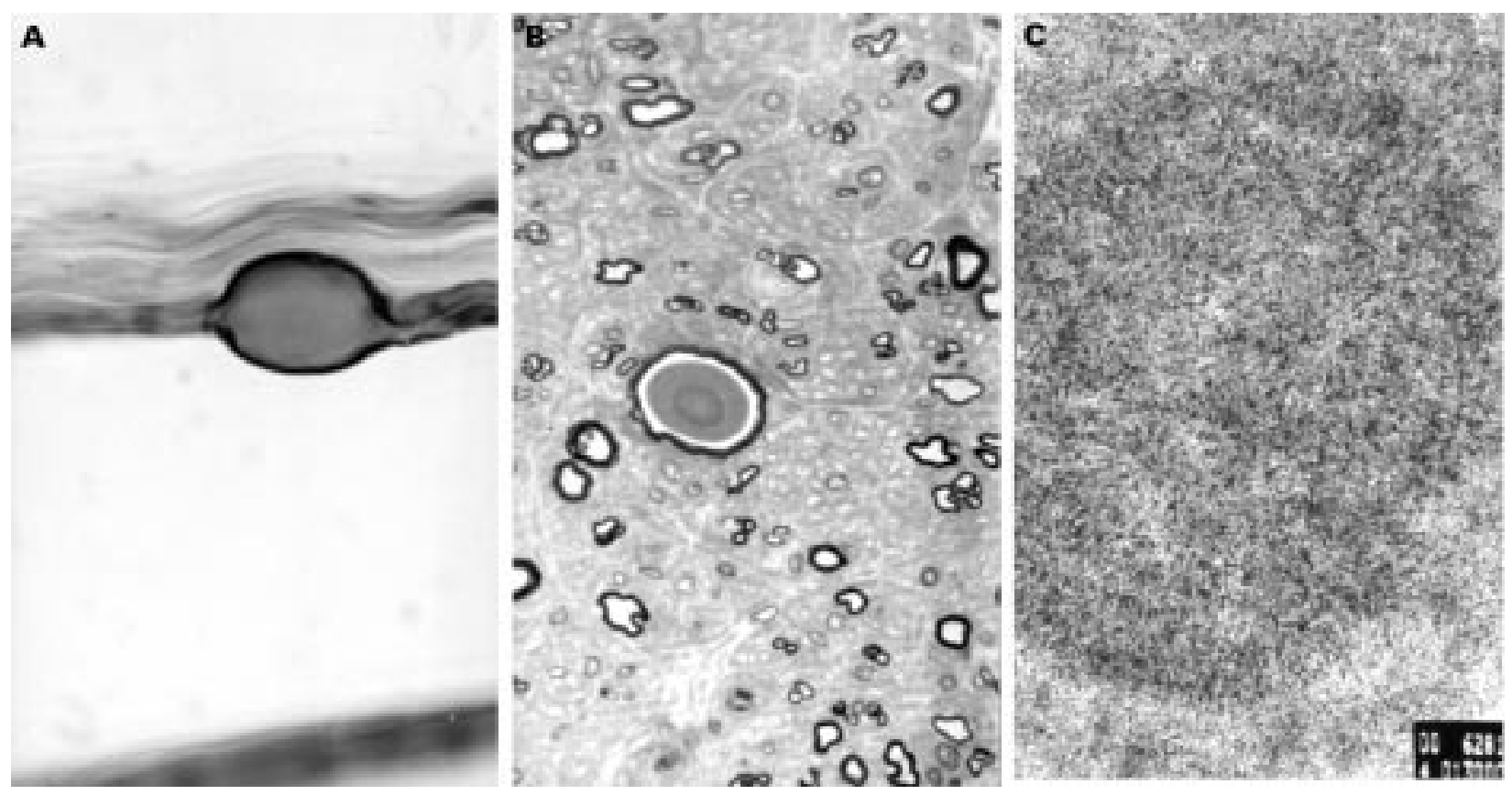

(A) Teased fibre preparation demonstrating an ellipsoid dilatation of an axon due to a polyglucosan body. (B) Resin preparation demonstating diffuse loss of myelinated fibres. One axon contains a large polyglucosan body (approximately $30 \mu \mathrm{m}$ ) with a round profile in transverse section. It has a laminated appearance with a slightly denser core. The surrounding myelin sheath is thinned. (originally $\times 600$. $(C)$ The polyglucosan body has an electron dense core with a less dense periphery and a characteristically fibrillary pattern (originally $\times 21100$ ).

impaired concentration and episodic memory. The neurological deterioration was gathering pace so that she was soon unable to walk without bilateral support around the house and required a wheelchair for longer distances. There was no history of neurological disease in her family, her parents were not consanguinous, and there was no history compatible with epilepsy or myoclonus from the patient.

On examination she had slow, hypomimic speech with a paucity of facial expression and variable dysphonia, extraocular eye movements were intact and there was no jaw jerk. In her limbs she had a coarse resting tremor, most marked in the right arm with no associated cerebellar signs but cogwheeling rigidity and bradykinesia. There was wasting in the small muscles of the hands and below the level of the knees bilaterally with mild weakness of all ankle movements and high arched feet. Deep tendon reflexes were absent at the ankle, brisk at the knees, and associated with bilateral extensor plantar responses. Sensation to vibration was absent to the mid-shins and impaired to light touch and pin prick to the knees. Her gait was slow, festinating, and bradykinetic. Formal neuropsychological evaluation disclosed impaired mental arithmetic, immediate and delayed recall, weak verbal fluency, and impaired executive function suggesting frontal lobe dysfunction. Tests of concentration, naming, and visuospatial analysis were normal.

Cranial CT was normal and a whole spine MRI demonstrated moderate degenerative changes only. No improvement in objective measurements of extrapyramidal dysfunction were seen with an incremental apomorphine test or more prolonged oral dopamine challenge. Neurophysiology showed changes compatible with a diffuse axonal neuropathy but extensive blood and serological tests failed to disclose a cause for this so a sural nerve biopsy was taken.

A $1 \mathrm{~cm}$ length of sural nerve was submitted for histopathological examination. Ten nerve fascicles were present in cross section, all of which showed moderate diffuse loss of both small and large myelinated axons. The presence of occasional axonal clusters were indicative of axonal sprouting. Several axons (almost one per fascicle on average, two within some facsicles) contained large, rounded intraaxonal inclusions which were metachromatic with toluidine blue staining. The inclusions, which were a maximum of $30 \mu \mathrm{m}$ in diameter, had a darker staining centre with a lighter halo and stained strongly positive with periodic acid Schiff (PAS). The appearances were typical of polyglucosan bodies. Teased fibre preparations demonstrated a few fibres in late stage wallarian degeneration and an occasional polyglucosan body (figure). The appearances were those of axonal neuropathy with polyglucosan body deposition and in the context of the clinical picture were consistent with a dignosis of APGBD.

\section{Discussion}

The presence of polyglucosan bodies on their own is a non-specific finding as they are also found in normal subjects with increasing age (although they occur less commonly in sural nerves compared with intramuscular nerves ${ }^{3}$ ), and occasionally in diabetic neuropathies and primary axonal neuropathies. ${ }^{4-6}$ However, they are also characteristically seen in some clinical situations including Lafora body disease and type IV glycogenosis, ${ }^{78}$ but they occur in much greater frequency in APGBD, particularly in nerve processes rather than perikarya (by contrast with Lafora bodies) and astrocytes. The diagnosis may be made by the association of 
the appropriate clinical phenotype with excessive numbers of polyglucosan bodies seen on peripheral nerve biopsy predominantly in myelinated fibres, ${ }^{12}{ }^{2-11}$ which is considered to be highly specific. Some authors have advocated axillary skin biopsy as a less invasive diagnostic method, which discloses an abundance of polyglucosan bodies in myoepithelial cells of apocrine glands. ${ }^{12}$

In one third of cases of APGBD there is a positive family history ${ }^{2}$ indicating a significant genetic component inherited in an autosomal recessive pattern. Polyglucosan bodies are seen throughout the central and peripheral nervous system as well as myocardium and non-neural tissues at postmortem, suggesting a generalised storage disorder. The presence of polyglucosan bodies before the age of 5 on peripheral nerve biopsy is always patholological and the diagnosis should also be considered in adults when there is more than one polyglucosan body per nerve fascicle or the presence of extraneuronal polyglucosan bodies or unusually large bodies $(>30 \mu \mathrm{m}) .{ }^{8}$ Histochemically they stain positively with PAS (diastase resistant), silver proteinate, and iodine, but are negative with Sudan black, luxol fast blue, and congo red. On electron microscopy they consist of branching filaments with amorphous and granular material. They are composed predominantly of abnormally branched glycogen (amylopectin) and are identical in composition to corpora amylacea and Lafora and Bielshowsky bodies.

Clinical phenomena usually consist of a mixture of lower and upper motor neuron signs, dementia, and urinary dysfunction. Features may be asymmetric, and reports of presentation with an amyotrophic lateral sclerosis picture $^{13}$ as well as multiple entrapment neuropathy, ${ }^{14}$ supranuclear gaze palsy and some features of parkinsonism ${ }^{15}$ and pure frontal lobe dementia ${ }^{16}$ have been made. The course of the disease is variable with survival of between 1 and 14 years in reported cases. ${ }^{2}$

The pathogenesis is not yet known but glycogen branching enzyme deficiencies in leucocytes and peripheral nerve but not in muscle have been noted in two Ashkenazi Jewish families. ${ }^{13} 17$ In addition, children of these patients have intermediate branching enzyme activity. A similar abnormality has not been found in sporadic cases or those from nonJewish descent, which suggests that APGBD is a heterogeneous condition but that a small subgroup may be explained on the basis of an inherited tissue specific defect of a branching isoenzyme.

In this patient the presence of an axonal neuropathy, mild frontal dementia, upper motor neuron signs, and a history of urinary dysfunction associated with excessive numbers of polyglucosan bodies on sural biopsy is characteristic of APGBD. It remains possible that the presentation of an extrapyramidal syndrome merely represents a chance association of a rare disorder with a more common one. However, the lack of reponse to dopamine, as well as the fact that polyglucosan bodies are known to accumulate pathologically within the CNS in APGBD, seems to indicate that it is more likely to be directly the result of the more widespread pathological process and is almost certainly another example of the heterogenous nature of this unusual disease.

1 Robitaille Y, Carpenter S, Karpati G, et al. A distinct form of polyglucosan disease with massive involvement of central
and peripheral neuronal processes and astrocytes. Brain 1980;103:316-36.

2 Cafferty MS, Lovelace RE, Hays AP, et al. Polyglucosan body disease. Muscle and Nerve 1991;14:102-107.

3 Bersen RAJAM, Busard HLSM, Ter Laak HJ, et al. Polyglucosan bodies in intramuscular motor nerves. Acta Neuropathol 1989;77:629-33.

4 Busard HLSM, Gabreels-Festen AAWM, van t'Hoff MA, et al. Polyglucosan disease in sural nerve biopsies. Acta Neuropathol 1990;80:554-7.

5 Mancardi GL, Schenone A, Tabaton M, et al. Polyglucosan bodies in the sural nerve of a diabetic patient with polyneuropathy. Acta Neuropathol 1985;66:83-6.

6 McMaster KR, Powers JM, Hennigar GR, et al. Nervous system involvement in type IV glycogenosis. Arch Pathol Lab Med 1979;103:105-11. $7 \begin{aligned} & \text { Yoshikawa H, Dyck PJ, Poduslo JF, et al. Polyglucosan body } \\ & \text { axonal enlargement increases myelin spiral length but not }\end{aligned}$ lamellar number. 7 Neurol Sci 1990;98:107-17.

8 Midroni G, Bilbao JM. Biopsy diagnosis of peripheral neuropathy. Boston: Heinemann, 1995.

9 Vos AJM, Joosten EMG, Gabriels-Festen AAWM. Adult polyglucosan disease: clinical and nerve biopsy findings in two cases. Ann Neurol 1983;13:440.

10 Gray F, Gherardi R, Marshall A, et al. Adult polyglucosan disease. F Neuropathol Exp Neurol 1988;47:459-74.

11 Lossos A, Brash V, Soffer D, et al. Hereditary branching enzyme deficiency in adult polyglucosan body disease: a possible metabolic cause in two patients. Ann Neurol 1991; 30:655-62.

12 Busard HLSM, Gabreels-Festen AAWM, Reiner WO, et al. Adult polyglucosan disease: the diagnostic value of skin biopsy. Ann Neurol 1991;29:448-51.

13 McDonald TD, Faust PL, Bruno CL, et al. Polyglucosan body disease simulating amyotrophic lateral sclerosis. Neurology 1993;43:785-90.

14 Gil-Neciga E, Pareja JA, Chincon I, et al. Multiple entrapment neuropathies in adult polyglucosan disease. Neurologia 1995;10:167-70.

15 Kosaka K, Matsushita M, Oyanagi S, et al. Pallido-nigroluysial atrophy with massive appearance of corpora amylacea in the CNS. Acta Neuropathol 1981;53:169-72.

16 Boulan-Predseil P, Vital A, Brochet B, et al. Dementia of frontal lobe type due to adult polyglucosan disease. $\mathrm{F} \mathrm{Neu}$ rol 1995;242:512-6.

17 Bruno C, Servidei S, Shanske S, et al. Glycogen branching enzyme deficiency in adult polyglucosan disease. Ann Neurol 1993;33:88-93.

18 Suzuki K, David E, Kutschman B. Presenile dementia with lafora-like intraneuronal inclusions. Arch Neurol 1979;25: 69-70.

19 Peres N, DiMauro S, Roxburgh V. Adult polysaccharidosis: clinicopathological, ultrastructural and biochemical features. Arch Neurol 1979;36:840-5.

20 Okamoto K, Llena JF, Hirano A. A type of adult polyglucosan disease. Acta Neuropathol (Berlin) 1982;58: polyg 7 .

21 Sugiyama H, Hainfellner JA, Lassmann H, et al. Uncommon types of polyglucosan bodies in the human brain: disribution and relation to disease. Acta Neuropathol (Berlin) 1993;86:484-90.

22 Matsumuro K, Izumo S, Minauchi Y, et al. Chronic demyelinating neuropathy and intra-axonal polyglucosan bodies. Acta Neuropathol (Berlin) 1993;86:95-9. 